\title{
IMPACT OF THE CHEMICAL FORM OF IN-CONTAINMENT SOURCE ON FISSION PRODUCT RELEASE FROM WWER-1000/V-320 TYPE NPP CONTAINMENT DURING LOCA
}

\author{
ADAM KECEK \\ Department of Nuclear Reactors, Faculty of Nuclear Sciences and Physical Engineering, Czech Technical \\ University in Prague \\ correspondence: kecekada@fjfi.cvut.cz
}

\begin{abstract}
Nuclear power plant accidents may be followed by a release of fission products into the environment. This release is dependent on several phenomena, such as chemistry, pressure, type of the accident etc. The aim of this paper is to assess the impact of the chemical form of iodine on the fission product release into the environment.
\end{abstract}

KEYWORDS: NPP, LOCA, iodine, containment, COCOSYS, fission products transport, WWER$1000 / \mathrm{V}-320$.

\section{INTRODUCTION}

Fission product behaviour and its simulation recently become more important. Nuclear power plant accidents in past decades revealed the need of proper definition and calculation of fission product mass entraining the environment. To successfully calculate such phenomena, one has to specify the in-containment source correctly. Several different approaches existing up to date vary in the mass, the chemical form or time characteristics. This paper is focused on assessment of the impact of the chemical form of iodine release, which is well known for its extensive range of chemical compounds and reactions within the containment. A fundamental opinion on the complexity of iodine chemistry in the containment during loss-of-coolant accidents can be obtained from Fig. 1. Used models, codes and brief overview on existing approaches are presented further.

\section{DesCRIPTION OF COCOSYS}

The COntainment COde SYStem is a lumped parameter computer code developed and maintained at Gesellschaft für Reaktorsicherheit (GRS mbH). It is used for best-estimate analysis of lightwater reactor containments during severe accidents. The code itself consists of several modules, which calculate all relevant phenomena. The thermal hydraulic (THY) module solves the pressure and temperature build-up history together with mass and energy flow. Furthermore it can simulate behaviour of engineering systems like valves, fans, pumps and sprays. A feedback from aerosol and fission products is also considered. The aerosol fission product (AFP) module is used to estimate the behaviour and transport of fission products and aerosols within the containment. The core concrete interaction (CCI) module provides an investigation of interaction of the molten core with concrete structures during severe accidents. All men-

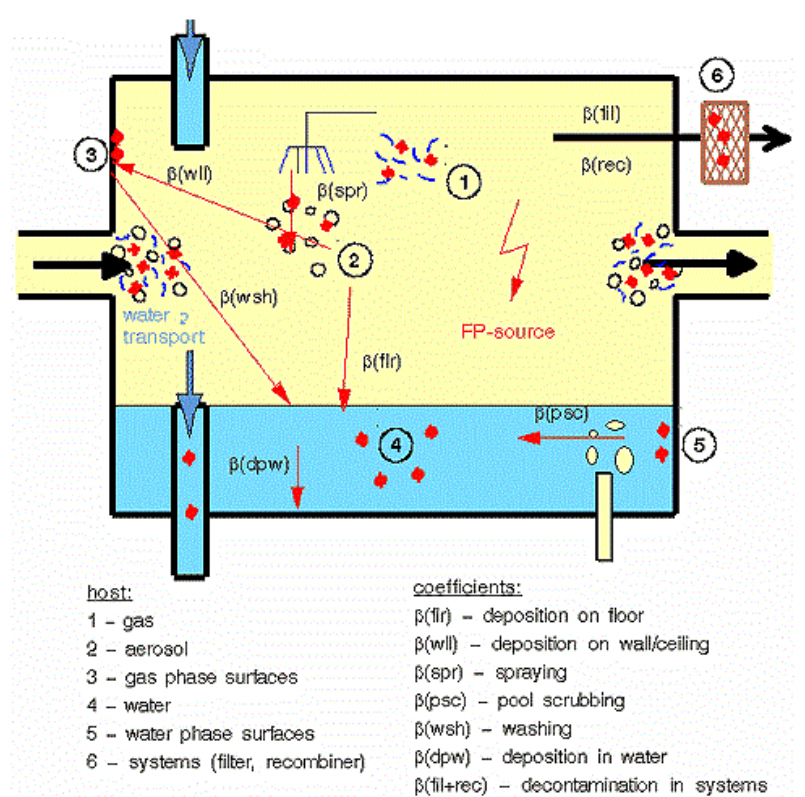

Figure 1. Scheme of iodine chemistry in NPP containment [1].

tioned modules are coupled to provide the desired feedback on relevant phenomena. Furthermore, COCOSYS provides a coupling option with several codes like ATHLET to simulate primary circuit behaviour or a CFD code for detailed analysis [2].

COCOSYS has been validated against several validation experiments and is often used in safety analysis of NPP concepts and existing power plants including WWER type NPPs [2].

\section{WWER-1000/V-320 MODEL DESCRIPTION}

The WWER-1000/V-320 type NPP containment is a cylindrical shaped building made of pre-stressed 
concrete with an inner steel liner. For thermal hydraulic calculations, the inner volume has to be divided into several smaller rooms. The presented model provides an approximation based on 20 volumes, so called nodes, which simulate the real space surrounded by the building. These volumes are connected through junctions providing mass and energy transfer. The walls, floor, ceiling and inner structures are also modeled to provide realistic heat transfer. Furthermore the containment spray systems are also modeled. Two large nodes (ENVIRON and BUILDING) simulate the outer volume surrounding the containment. These provide boundary conditions of the problem. The nodalisation of the containment is presented in Tab. 1.

\begin{tabular}{|c|c|c|}
\hline Compartments & Nodes & Description \\
\hline E1 & $\begin{array}{l}\text { ENVIRON } \\
\text { BUILDING }\end{array}$ & $\begin{array}{l}\text { Environment } \\
\text { Surrounding buildings }\end{array}$ \\
\hline IGA501 & GA501 & $\begin{array}{l}\text { Upper part of the } \\
\text { reactor shaft }\end{array}$ \\
\hline IGA301 & GA301A & $\begin{array}{l}\text { Lower part of the } \\
\text { reactor shaft }\end{array}$ \\
\hline IGA401 & GA401A2 & Spent fuel pools \\
\hline IGA701 & GA701 & Reactor hall \\
\hline IASUPP & $\begin{array}{l}\text { CNT-U1 } \\
\text { CNT-U2 }\end{array}$ & $\begin{array}{l}\text { Upper section of the } \\
\text { building surrounded by the } \\
\text { containment wall and steam } \\
\text { generator boxes }\end{array}$ \\
\hline IASGBOX1 & SGBOX-1 & Steam generator box 1 \\
\hline IASGBOX2 & SGBOX-2 & Steam generator box 2 \\
\hline IASMED & $\begin{array}{l}\text { CNT-M1 } \\
\text { CNT-M2 }\end{array}$ & $\begin{array}{l}\text { Middle section of the buil- } \\
\text { ding at the containment wall }\end{array}$ \\
\hline IASLOW & $\begin{array}{l}\text { CNT-L1 } \\
\text { CNT-L2 } \\
\text { GA311 } \\
\text { GA306-1 } \\
\text { GA306-2 } \\
\text { GA306-3 }\end{array}$ & $\begin{array}{l}\text { Lower section of the } \\
\text { containment building }\end{array}$ \\
\hline IGA201 & GA201 & Spray water sump \\
\hline IASTL22 & TL22P & Fan system \\
\hline
\end{tabular}

TABLE 1. Containment discretization.

The simulation of containment leak is maintained by atmospherical junction. This is estimated to follow the limits and conditions of operation of the WWER1000/V-320 type containment. The junction itself is placed in the upper part of the containment connecting the reactor hall and environment. The reason for choosing this position is to simulate shortest and easiest way for ejecting the material from containment into the environment.

For calculation of fission product and aerosol behaviour the containment building has to be divided into volumes so-called compartments formed by nodes. Thus, compartments provide coarser fragmentation of the containment building. The fragmentation of the containment volume for iodine calculations is presented in Tab. 1 and Fig. 2. The calculations were done using the AFP and THY COCOSYS computational modules.

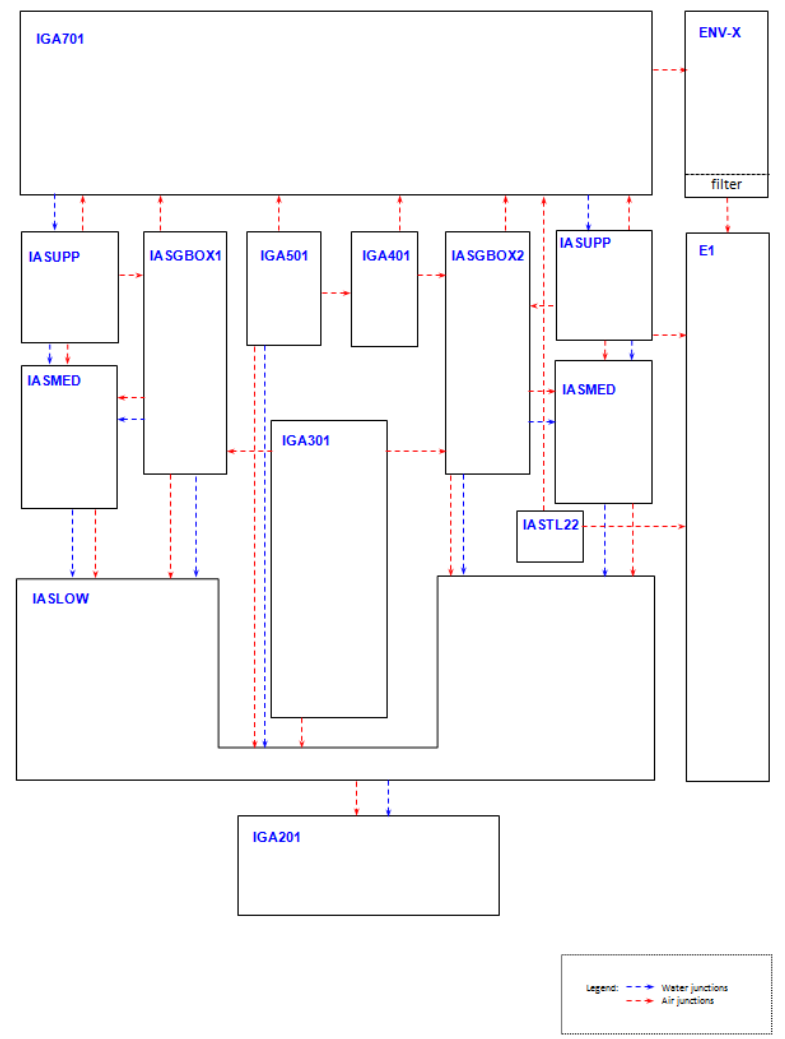

FIGURE 2. Iodine compartment discretization of WWER-1000/V320 NPP containment.

\section{Initial And Boindary CONDitions}

Before the accident, the nuclear power plant is operated at $104 \%$ nominal power. The initiating event is a primary circuit hot leg guillotine rupture at $t=0 \mathrm{~s}$ with leak through breaks of equivalent diameter equal to $850 \mathrm{~mm}$ (large break LOCA) into one of the steam generator boxes. Moreover, following assumptions are taken into account $[3$ :

- loss of on-site power,

- only $1 / 3$ of safety systems in operation (according to conservative approach),

- no action expected from operators.

The entrainment of fission products into the containment is maintained through the break in the primary hot leg. The ejecting coolant brings the fission products and aerosols released from the core. In accordance with local practice the in-containment source term is based on Ref. 4]. Following this approach failure of all fuel assembly is expected.

In addition, whole fission product mass released into the primary circuit is transferred into the containment. This means that no fission products remain in the primary circuit.

The Ref. [4 divides the problem of fission product release into two areas, namely normal and core melt. 
The investigated accident does not expect the molten core, so only the pellet-cladding gap inventory is taken into account. The fraction of released fission products is given in Tab. 2

\begin{tabular}{|c|c|c|}
\hline Fission product & $\begin{array}{l}\text { Pellet-cladding gap } \\
\text { release fraction } \\
(30-1800 \mathrm{~s})\end{array}$ & $\begin{array}{l}\text { Fuel melt release } \\
\text { fraction } \\
(1800-4680 \mathrm{~s})\end{array}$ \\
\hline $\mathrm{I}, \mathrm{Br}$ & 0.05 & 0.95 \\
\hline $\mathrm{Xe}, \mathrm{Kr}$ & 0.05 & 0.35 \\
\hline $\mathrm{Cs}, \mathrm{Rb}$ & 0.05 & 0.25 \\
\hline $\mathrm{Te}, \mathrm{Sb}, \mathrm{Se}$ & 0.00 & 0.05 \\
\hline $\mathrm{Ba}, \mathrm{Sr}$ & 0.00 & 0.02 \\
\hline $\begin{array}{l}\mathrm{Ru}, \mathrm{Rh}, \mathrm{Pd}, \mathrm{Mo}, \\
\mathrm{Tc}, \mathrm{Co}\end{array}$ & 0.00 & 0.0025 \\
\hline $\begin{array}{l}\mathrm{La}, \mathrm{Zr}, \mathrm{Nd}, \mathrm{Eu}, \\
\mathrm{Nb}, \mathrm{Pm}, \mathrm{Pr}, \mathrm{Sm}, \\
\mathrm{Y}, \mathrm{Cm}, \mathrm{Am}\end{array}$ & 0.00 & 0.0005 \\
\hline $\mathrm{Ce}, \mathrm{Pu}, \mathrm{Np}$ & 0.00 & 0.0002 \\
\hline
\end{tabular}

TABLE 2. Fraction of the fission products released during an accident [4.

A research on available in-containment fission product source showed a significant difference between each approach. Synchronization efforts on this problem throughout Europe pointed out the diversity of the iodine species, the target medium (water, sump or aerosol) and also the fraction of the core inventory released [5. It has to be mentioned that there is no information on time characteristics of the release. Based on this it was decided to test, whether the chemical form and also the target part of the zone has any influence on iodine mass entraining the environment. The time characteristics and fraction released was adopted from Ref. 4. Finally, five calculations were done in this sensitivity study, where the distribution of iodine mass varied in chemical form. In addition, the target part of the zone was changed too. Overview on all calculations is given in Tab. 3 .

\begin{tabular}{|c|c|c|c|}
\hline Calculation & $\begin{array}{l}\text { Chemical } \\
\text { form }\end{array}$ & $\begin{array}{l}\text { Target part } \\
\text { of the zone }\end{array}$ & $\begin{array}{l}\text { Iodine mass } \\
\text { distribution }[\%]\end{array}$ \\
\hline $\mathrm{c} 00$ & $\begin{array}{l}\mathrm{CsI} \\
\mathrm{I}_{2} \\
\mathrm{CH}_{3} \mathrm{I}\end{array}$ & Atmospher $£^{1}$ & $\begin{array}{l}95 \\
4.85 \\
0.15\end{array}$ \\
\hline c01 & $\begin{array}{l}\mathrm{CsI} \\
\mathrm{I}_{2} \\
\mathrm{CH}_{3} \mathrm{I}\end{array}$ & Atmosphere & $\begin{array}{l}0.15 \\
95 \\
4.85\end{array}$ \\
\hline c02 & $\begin{array}{l}\mathrm{CsI} \\
\mathrm{I}_{2} \\
\mathrm{CH}_{3} \mathrm{I}\end{array}$ & Sump & $\begin{array}{l}0.15 \\
95 \\
4.85\end{array}$ \\
\hline $\mathrm{c} 03$ & $\begin{array}{l}\mathrm{CsI} \\
\mathrm{I}_{2} \\
\mathrm{CH}_{3} \mathrm{I}\end{array}$ & Atmosphere & $\begin{array}{l}4.85 \\
0.15 \\
95\end{array}$ \\
\hline $\mathrm{c04}$ & $\begin{array}{l}\mathrm{CsI} \\
\mathrm{I}_{2} \\
\mathrm{CH}_{3} \mathrm{I}\end{array}$ & Sump & $\begin{array}{l}4.85 \\
0.15 \\
95\end{array}$ \\
\hline
\end{tabular}

TABLE 3. Overview on calculated variants.
The total mass of fission products in the core is based on values provided in Ref. [3. The total amount of iodine used in this calculation is $22.7 \mathrm{~kg}$. It has to be noted that not all the fission product mass is expected to be radioactive. This study calculates the behavior of the whole mass of iodine entraining the containment.

\section{Results And COMParison}

The calculations were done for $14400 \mathrm{~s}$, what equals to 4 hours. This time range was chosen to be representative as the testing calculations showed that the marginal contribution to the mass ejecting the containment during the accident is within first two hours. Calculation c04 was neglected due to numerical error.

\begin{tabular}{|c|c|c|c|c|}
\hline No. & Description & & Mass [g] & $\begin{array}{l}\text { Deviation } \\
\text { from c00 [\%] }\end{array}$ \\
\hline $\mathrm{c00}$ & $\begin{array}{l}\text { Base case }(95 \% \mathrm{CsI} \\
\left.4.85 \% \mathrm{I}_{2}, 0.15 \% \mathrm{CH}_{3} \mathrm{I}\right)\end{array}$ & $\mathrm{A}$ & $4.94 \times 10^{-3}$ & 0.00 \\
\hline c01 & $\begin{array}{l}\text { Modified iodine mass } \\
\text { distribution } \\
\left(95 \% \mathrm{I}_{2}, 4.85 \% \mathrm{CH}_{3} \mathrm{I} \text {, }\right. \\
0.15 \% \mathrm{CsI})\end{array}$ & A & $2.33 \times 10^{-2}$ & 371.51 \\
\hline $\mathrm{c} 02$ & $\begin{array}{l}\text { Modified iodine mass } \\
\text { distribution } \\
\left(95 \% \mathrm{I}_{2}, 4.85 \% \mathrm{CH}_{3} \mathrm{I} \text {, }\right. \\
0.15 \% \mathrm{CsI})\end{array}$ & $\mathrm{S}$ & $4.78 \times 10^{-3}$ & -3.39 \\
\hline c03 & $\begin{array}{l}\text { Modified iodine mass } \\
\text { distribution } \\
\left(95 \% \mathrm{CH}_{3} \mathrm{I}, 4.85 \% \mathrm{CsI} \text {, }\right. \\
\left.0.15 \% \mathrm{I}_{2}\right)\end{array}$ & $\mathrm{A}$ & $1.14 \times 10^{-1}$ & 2204.44 \\
\hline c04 & $\begin{array}{l}\text { Modified iodine mass } \\
\text { distribution } \\
\left(95 \% \mathrm{CH}_{3} \mathrm{I}, 4.85 \% \mathrm{CsI} \text {, }\right. \\
\left.0.15 \% \mathrm{I}_{2}\right)\end{array}$ & $\mathrm{S}$ & err & err \\
\hline
\end{tabular}

TABLE 4. Overview on calculation and results.

The trend of the release is in good agreement with all calculations except c03, where almost constant release rate can be observed. The ejected mass in calculations c00 through c02 shows a massive growth of the release within the first hour, then it slows down and in long time view it shows stabilization of the mass entraining the environment. This may be caused by several phenomena, such as sedimentation or wash down of fission products from walls into the sump.

The worst case presented in this sensitivity analysis is c03, where the main mass was injected as organic iodine into the atmosphere. It has to be noted that this form is not expected to be a typical contributor to the in-containment source, thus the results seem to be unrealistic.

The second worst case is c01, where the iodine in elemental form is injected into the gas part of the zone. This leads to a high release of iodine into the environment. In accordance to Ref. [6] the elemental

\footnotetext{
${ }^{1}$ The CsI aerosol can be injected only into the gas part of the zone.
} 

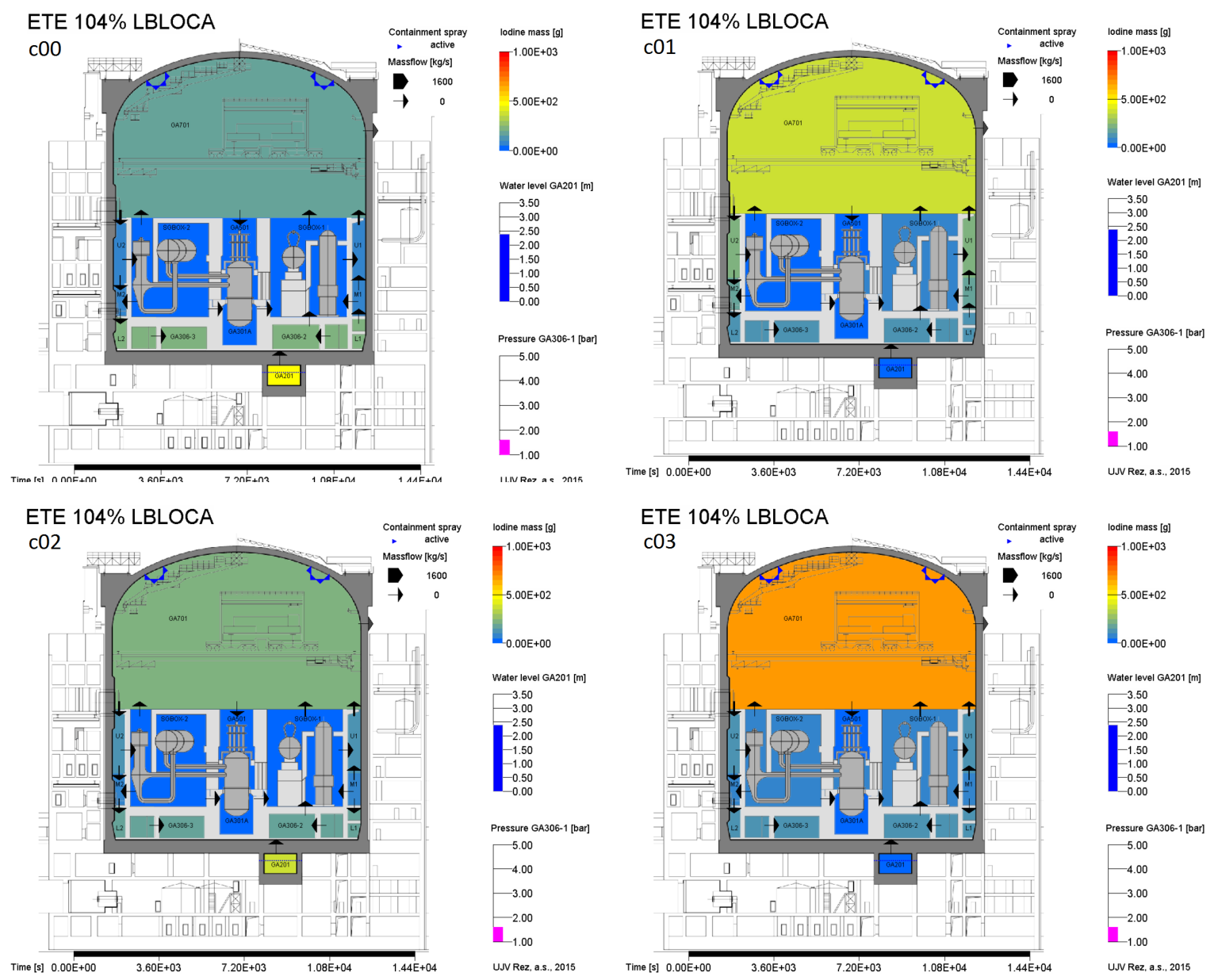

Figure 3. Distribution of iodine in the containment (c00-c03, $14400 \mathrm{~s})$.

iodine is one of the main options of iodine mass release into the environment.

The base case c00 provided results lower than the two calculations presented before. The mass behaves significantly different as the compound is expected to be in aerosol particle form.

The lowest release was calculated for elemental iodine injected into the sump part. This may be caused by high solubility of iodine species.

The results are presented in Tab. 4 and Fig. 4

The distribution within the containment varies for each calculation. In the case of c00 the mass is centralized in the containment sump. This may be induced by the aerosol wash down. The c01 shows significant concentration in the reactor hall. This is probably caused by the chemical form, as the injection was in form of elemental iodine into the atmosphere. Furthermore, $\mathrm{c} 02$ provides results close to the $\mathrm{c} 00$ calculation. The injected iodine might be dissolved in water and then washed down into the containment sump. Finally the c03 calculation shows distribution close to the c01. This is again induced by the injection of iodine as a gas. The iodine mass is mainly distributed within the reactor hall. The results of the calculations c00 through c03 at $14400 \mathrm{~s}$ are presented in Fig. 3

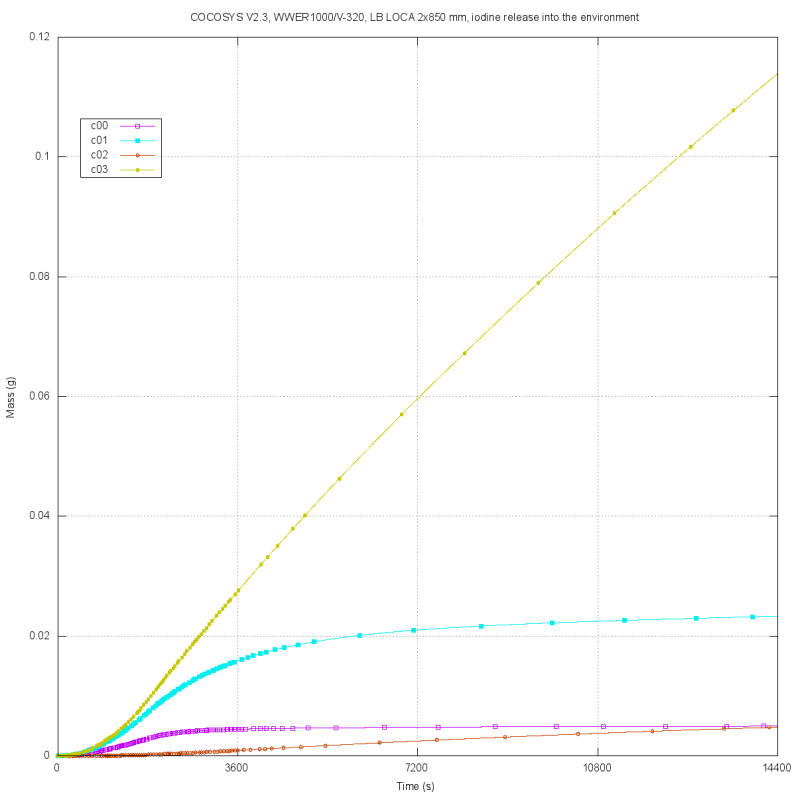

Figure 4. Iodine release into the environment (c00-c03, 14400 s). 


\section{Conclusion}

The presented calculations proved a significant impact of the chemical form of iodine on release into the environment. Furthermore the injected phase (water, gas) is also an important factor significantly influencing the ejected mass. Future effort should be made on the assessment of the in-containment source, e.g. the time range and the fraction of ruptured fuel assembly.

\section{REFERENCES}

[1] IRSN. The ASTEC software package. http://www.irsn.fr/EN/Research/ Scientific-tools/Computer-codes/Pages/ The-ASTEC-Software-Package-2949.aspx
[2] W. Klein-Heßling, et al. COCOSYS V2.4 User's Manual. Gesellschaft für Anlagen- und Reaktorsicherheit (GRS) mbH, 2010.

[3] A. Kecek. Testovací výpočty úniku štěpných produktů z kontejnmentu JE Temelín v průběhu LOCA události programem COCOSYS. Tech. Rep. Z4339, ÚJV, 2016.

[4] U.S. Nuclear Regulatory Commission. Alternative radiological source terms for evaluating design basis accidents at nuclear power reactors, 2000. Regulatory Guide 1.183 .

[5] Nuclear fuel behaviour in loss-of-coolant accident (LOCA) conditions. Tech. Rep. 6846, NEA OECD, 2009.

[6] U.S. Nuclear Regulatory Commission. Methods and assumptions for evaluating radiological consequences of design basis accidents at light-water nuclear power reactors, 2003. Regulatory Guide 1.195. 